\title{
Effect of Physical Education-based stretching programs on hamstring extensibility in high school students: A systematic review
}

\author{
Efecto de los programas de estiramiento en Educación Física sobre la extensibilidad de la \\ musculatura isquiosural en estudiantes de Educación Secundaria: Una revisión sistemática \\ Carlos Alberto Becerra-Fernández ${ }^{1}$, Daniel Mayorga-Vega ${ }^{2}$, Rafael Merino-Marban ${ }^{3}$ \\ 1 I.E.S. Sagrado Corazón. España. \\ 2 Department of Didactic of Musical, Plastic and Corporal Expression. Faculty of Humanities and Education Sciences. University of Jaén. España. \\ 3 Facultad de Ciencias de la Educación. Universidad de Málaga. España.
}

\author{
CORRESPONDENCIA: \\ Daniel Mayorga-Vega \\ dmayorgavega@gmail.com
}

Fecha Recepción: junio de 2018 • Fecha Aceptación: noviembre de 2018

\section{CÓMO CITAR EL ARTÍCULO:}

Becerra-Fernández, C. A., Mayorga-Vega, D., \& Merino-Marban, R. (2020). Effect of Physical Education-based stretching programs on hamstring extensibility in high school students: A systematic review. Cultura, Ciencia y Deporte, 15(43), 63-73.

\begin{abstract}
The purpose of the present review was to examine the effects of Physical Education-based stretching programs on hamstring extensibility in high school students. Relevant studies were searched from 10 databases. The results suggested that students should performed stretching programs at least for a duration of 5-6 weeks, a frequency of twice a week, and a volume per session of 30-60 s (20-30 s per set) to obtain improvements on the hamstring extensibility. Stretching programs with higher duration, frequency and volume seems to obtain greater effects. Although the most studies obtained flexibility improvements using static techniques, dynamic stretching exercises performed in a controlled manner also produced improvements and they were safety. After a four-week detraining period, students reverted back to their baseline levels. Teachers should implement stretching programs to improve the students' flexibility during the Physical Education classes.
\end{abstract}

Key words: Hamstring muscles extensibility, range of motion, flexibility program, secondary school, adolescents.

\section{Resumen}

El objetivo de la presente revisión fue examinar los efectos de los programas de estiramiento en Educación Física sobre la extensibilidad de la musculatura isquiosural en estudiantes de Educación Secundaria. Los estudios relevantes se buscaron en 10 bases de datos. Los resultados sugirieron que los estudiantes deberían realizar programas de estiramientos con al menos una duración de 5-6 semanas, una frecuencia de dos veces por semana, y un volumen por sesión de 30-60 s (20-30 s por serie) para obtener mejoras en la extensibilidad de la musculatura isquiosural. Programas de estiramientos con una mayor duración, frecuencia y volumen parecen obtener mayores efectos. Aunque la mayoría de los estudios obtuvieron mejoras de la flexibilidad usando técnicas estáticas, los ejercicios dinámicos realizados de forma controlada también produjeron mejoras y fueron seguros. Después de un período de desentrenamiento de cuatro semanas, los estudiantes volvieron a sus niveles basales. Los profesores deberían implementar programas de estiramiento para mejorar la flexibilidad de los estudiantes durante las clases de Educación Física.

Palabras clave: Extensibilidad de la músculatura isquiosural, rango de movimiento, programa de flexibilidad, Educación Secundaria Obligatoria, adolescentes. 


\section{Introduction}

Nowadays physical fitness is considered one of the most important health markers in adolescence (Ortega, Ruiz, Castillo \& Sjöström, 2008), where flexibility (i.e., the physical fitness component characterized as the skill to execute movements with a wide range of motion, $\mathrm{Me}$ rino Marban, López Fernández, Torres Luque \& Fernández Rodríguez, 2011) is an essential component of health-related physical fitness (National Association for Sports and Physical Education, 2005). Particularly, low hamstring extensibility (i.e., the property of the body tissues for lengthening or extending due to stretching, which in part, it conditions the individual's flexibility, Merino Marban \& Fernández Rodriguez, 2009; Merino Marban et al., 2011) has been associated with several spinal disorders such as thoracic hyperkyphosis (Fisk, Baigent, \& Hill, 1984), spondylolysis (Standaert \& Herring, 2000), disc herniation (Harvey \& Tanner, 1991), changes in lumbopelvic rhythm (López-Miñarro \& Alacid, 2009) and low back pain (Sjölie, 2004). Moreover, adolescents with an inadequate hamstring extensibility seem to have a higher risk of current low back pain (Feldman, Shrier, Rossignol, \& Abenhaim, 2001; Jones, Stratton, Reilly \& Unnithan, 2005; Sjölie, 2004) and neck tension (Mikkelsson et al., 2006), as well as a higher risk of low back pain later during adulthood (Hestbaek, Leboeuf-Yde, Kyvik, \& Manniche, 2006; Kujala, Taimela, Salminen \& Oksanen, 1994).

Unfortunately, flexibility is characterized to be in a permanent involution process (Chodzko-Zajko et al., 2009). Actually, many investigations have revealed muscle shortening even in school age children, especially in the hamstrings (Brodersen, Pedersen \& Reimers, 1994; Harreby et al., 1999; Kanasova, 2008; Rodríguez, Santonja, López-Miñarro, Sainz de Baranda \& Yuste, 2008; Santonja, Sainz de Baranda \& Rodríguez, 2007; Vidal, Almiñana, Zamorano \& Almiñana, 2011). For instance, in Spain over one in five adolescents have limited hamstring extensibility (Castro-Piñero et al., 2013; Ortega et al., 2005). For this reason, it is essential applying programs that pursue flexibility development and maintenance during adolescence (Borras et al., 2007; Kanasova, 2008; Sainz de Baranda, 2009). Therefore, health promotion policies should also be designed to identify adolescents with low hamstring extensibility, as well as to encourage them to achieve health-enhancing levels (Ortega et al., 2008).

The subject of physical education (PE) might play an important role in this public health issue. Shortened hamstring muscles could be addressed proactively by systematically performing stretching exercises during PE sessions (Merino-Marban, Mayorga-Vega,
Fernández-Rodríguez, Vera Estrada, \& Viciana, 2015; Rodríguez et al., 2008; Santonja Medina, Sainz de Baranda Andújar, Rodríguez García, López Miñarro \& Canteras Jordana, 2007; Thacker, Gilchrist, Stroup \& Kimsey, 2004; Van Rensburg \& Coetzee, 2014). Since $\mathrm{PE}$ has the potential of optimizing environmental conditions and giving prolonged feedback that reaches a large percentage of the population, Rodríguez et al. (2008) suggest that the PE class must be an ideal setting for hamstring shortness prevention. Additionally, the high prevalence of sagittal spinal misalignments makes necessary to include stretching exercises for the hamstring stretches in PE classes (Santonja, Rodríguez, Sainz de Baranda \& López Miñarro, 2004). On the other hand, due to the brief nature of this kind of interventions stretching exercises do not interfere with the planning of other class content within flexibility programs (Coledam et al., 2012).

Several previous studies have shown that a PE-based static stretching program improves students' hamstring extensibility in both primary (Mayorga-Vega, Merino-Marban, Vera-Estrada \& Viciana, 2014b; Merino-Marban et al., 2015; Sánchez Rivas, Mayorga-Vega, Fernández-Rodríguez \& Merino-Marban, 2014) and high school students (Becerra-Fernández, Merino-Marban \& Mayorga-Vega, 2016; Mayorga-Vega, Merino-Marban, Real \& Viciana, 2015; Sainz de Baranda, 2009; Van Resbourg \& Coetzee, 2014). There are also some previous studies that have examined the effectiveness and safety of a dynamic stretching program in high school students (Becerra-Fernández et al., 2016; Van Rensburg \& Coetzee, 2014; Vidal, 1995). Recently, Becerra-Fernández and Merino-Marban (2015) performed a systematic review of the effect of PE-based stretching programs on hamstring extensibility in primary schoolchildren. Unfortunately, to our knowledge there is not any systematic review about the efficacy of hamstring stretching programs in high school students. Consequently, the main purpose of the present review was to examine the scientific literature on the effects of physical education-based stretching programs on hamstring extensibility in high school students aged $12-17$ years

\section{Method}

Data sources and search strategy

The following 10 electronic databases were searched from their inception through January 2016: SportDiscus, Web of Science, Scopus, ASSIA, CINAHL, Cochrane, IBSS, Proquest Dissertation and Theses, Proquest Education Journals, and ERIC. The search- 
es were carried out in the search field type "Title, abstract, and keywords" or equivalent. The search terms used were based on four concepts: (1) flexibility, (2) intervention, (3) hamstring extensibility test, and (4) population/PE setting. The terms of the same concept were combined together with the Boolean operator "OR" and then the four concepts were combined using the Boolean operator "AND". The truncated root of certain terms was followed by an asterisk to include multiple variants. The keywords that consisted of more than one word were enclosed in quotes.

The specific search syntaxis used in the present review was the following: (flexibility OR elasticity OR extensibility OR ROM OR "range of motion" OR "range of movement" OR stretch*) AND (training OR detraining OR program* OR intervention OR exercise*) AND ("straight leg raise" OR "straight-leg raise" OR "knee extension" OR "popliteal angle" OR "sit-and-reach" OR "sit and reach" OR "toe-touch" OR "toe touch" OR "standand-reach" OR "stand and reach" OR "finger to floor distance" OR "fingertip floor distance" OR "forward bend" OR "angular test*" OR "lineal test" OR hip* OR hamstring) AND (child* OR kid* OR adolescent* OR teenager* OR youth OR young OR pubertal OR pubescent* OR prepuberal OR prepubescent* OR preadolescent* OR boy* OR girl* OR schoolchild* OR student* OR pupil* OR education OR school OR "physical education" OR PE).

As a result of the selected studies from the Booleanbased database search, additional records were identified through other sources: (1) searching the reference lists of included studies and some related study reviews; (2) examining the reference citations in the Web of Science and Scopus databases; (3) searching the researchers' publications (first authors) in the Web of Science, Scopus and SportDiscus databases; (4) contacting by email with the corresponding authors (if they were not defined, the first author was used), and (5) screening the researchers' personal lists in ResearchGate and Google Scholar (first authors). No publication format, language or date restrictions were imposed. For practical reasons, the search, study selection and data collection were carried out for one researcher $(\mathrm{CABF})$.

\section{Study selection}

The selection criteria to identify studies that examined the hamstrings stretching programs on flexibility improvement in high school students were the following: (a) studies with apparently healthy participants who did not present any injury, physical and/or mental disabilities; (b) studies that assess the hamstring extensibility before and after the stretching program with tests widely accepted in the scientific literature (e.g., straight leg raise or knee extension tests, classic or modified sit-and-reach test); (c) studies in which participants' age ranged from 12-17 years; (d) studies which included control group, (e) and intervention programs were focused on hamstring stretching exercises.

\section{Data collection}

From each selected study the following data were extracted: Reference, sample size $(n)$, sex of participants, age of participants, duration of the program, frequency of the program, stretching volume, stretching intensity, stretching exercises, test protocols and results. Because identification of study features was usually explicitly stated in each of the primary articles, the use of more than one rather was deemed unnecessary. Based on Borenstein, Hedges, Higgins, and Rothstein (2009), the unstandardized mean difference $[D$ $=\left(\mathrm{Mean}_{\text {Post-intervention experimental }}-\mathrm{Mean}_{\text {Pre-intervention experimental }}\right)$ - (Mean Post-intervention control - Mean Post-intervention experimental $)]$ and standardized mean difference $(d=D / S D$ Pre-interven) were calculated. Based on the Cohen's (1992) benchmarks, effect sizes were interpreted as very low $(d=0.00-0.19)$, low $(d=0.20-0.49)$, moderate $(d=$ $0.50-0.79)$ and high $(d \geq 0.80)$.

\section{Results}

Figure 1 shows a flow chart of the study selection process. Of the 5,861 literature search results, 30 potentially relevant publications were identified and retrieved for a more detailed evaluation. A total of 20 studies were excluded because they did not meet the inclusion criteria, while 10 studies did. Subsequently, other modes of searching were performed and two new articles met the inclusion criteria, whereas one of them was excluded for duplicated information. Finally, 11 studies were included in the present review. The general characteristics of the studies which included hamstring stretching programs as a part of PE classes are shown in Table 1.

\section{Discussion}

Duration, frequency, volume and intensity of the development program

Regarding the duration of the program, the present systematic review found studies examining the effect of short-, middle- and long-term stretching programs. Although the results of the studies showed that the 
Table 1. General characteristics of the included studies

\begin{tabular}{|c|c|c|c|c|c|c|}
\hline \multirow{2}{*}{ Reference } & \multicolumn{2}{|c|}{ Sample } & \multirow[b]{2}{*}{ Duration (weeks) } & \multirow[b]{2}{*}{ Frequency (ses/ wk) } & \multirow[b]{2}{*}{ Session part } & \multirow[b]{2}{*}{ Technique } \\
\hline & Gender (n) & Age (years) & & & & \\
\hline $\begin{array}{l}\text { Becerra-Fernández et al. } \\
\text { (2016) }\end{array}$ & $q=102$ & $16-17$ & 12 & 2 & Warm-up/ cool-down & $\begin{array}{l}\text { Dynamic Active (soft repetitive } \\
\text { bounces) }\end{array}$ \\
\hline $\begin{array}{l}\text { Mayorga-Vega et al. } \\
(2015)\end{array}$ & $\begin{array}{l}\hat{o}=94 \\
+=86\end{array}$ & $12-14$ & 8 & $\begin{array}{l}\mathrm{EG1}=1 \\
\mathrm{EG} 2=2\end{array}$ & Cool-down & Static active \\
\hline $\begin{array}{c}\text { Van Rensburg \& Coetzee } \\
\text { (2014) }\end{array}$ & $q=100$ & $13-17$ & 6 & 3 & Warm-up & $\begin{array}{l}\text { Static passive (EG1-3) } \\
\text { Dynamic active (EG4) }\end{array}$ \\
\hline
\end{tabular}

\begin{tabular}{llllll}
\hline Kamandulis et al. (2013) & $\hat{o}=107$ & 15.1 & 5 & 2 & Warm-up \\
& $+=132$ & & & & Static active
\end{tabular}

\begin{tabular}{llllll} 
& & & \\
\hline Useros \& Campos (2011) & $+=23$ & $16-17$ & 5 & Warm-up \\
$\delta=10$ & & & Static passive
\end{tabular}

\begin{tabular}{cccccc}
\hline Sainz de Baranda (2009) & $\hat{\delta}=23$ & 13.7 & 31 & 2 & Warm-up/ Cool-down \\
$\rho=27$ & & & Static active (warm-up) Static \\
passive (cool-down)
\end{tabular}

\begin{tabular}{|c|c|c|c|c|c|c|}
\hline Rodríguez et al. (2008) & $\begin{array}{l}\hat{O}=21 \\
q=23\end{array}$ & 13.5 & 32 & 2 & Warm-up/ Cool-down & Static active \\
\hline Nelson \& Bandy (2004) & $\delta=69$ & 16.4 & 6 & 3 & Warm-up & Static passive \\
\hline
\end{tabular}

\begin{tabular}{|c|c|c|c|c|c|c|}
\hline Reid \& Mcnair (2004) & $\hat{0}=43$ & 15.8 & 6 & 5 & Warm-up & Static passive \\
\hline Rodríguez et al. (1999) & $\begin{array}{l}\hat{\partial}=18 \\
q=21\end{array}$ & 13.5 & 32 & 2 & Warm-up/ Cool-down & Static passive \\
\hline Vidal $(1995)^{\mathrm{b}}$ & $\begin{array}{l}\hat{0}=73 \\
q=90\end{array}$ & $16-17$ & 6 & 3 & Warm-up & Static/ Dynamic passive/ active \\
\hline
\end{tabular}

Note: $\hat{\delta}=$ Boys; $q=$ Girls; $E G=$ Experimental group. a - Data reported for the stretching program refers only to the hamstring muscle stretching (i.e., when stretching exercises for other muscles were performed, they were not considerate). When there were one-leg stretching exercises, volume data were reported considering the stretching load performed by each hamstring muscle. $b$ - Since pre-intervention scores were not reported, effects sizes could not be calculated. * $p<0.05$ 


\begin{tabular}{|c|c|c|c|c|}
\hline \multicolumn{3}{|l|}{ program $^{a}$} & \multirow{2}{*}{ Test } & \multirow{2}{*}{ Effect size (d) } \\
\hline Exercises & Volume (per session) & Intensity & & \\
\hline $\begin{array}{l}\text { Bipodal: Sitting with feet together. } \\
\text { Spine neutral position }\end{array}$ & $\begin{array}{c}8 \text { wk: } 2 \text { x } 60 \text { s (warm-up) } / 2 \text { x } 60 \text { s (cool-down) } \\
\text { Total: } 240 \mathrm{~s} \\
(4 \text { wk holidays) } \\
4 \text { wk: } 2 \times 60 \text { s (cool-down) } \\
\text { Total: } 120 \mathrm{~s}\end{array}$ & Feeling tightness, but no pain & Classic sit-and-reach & $\begin{array}{c}8 w k: D=2.5 \mathrm{~cm} \\
d=0.39^{*} \\
8+4 \text { wk: } D=5.4 \mathrm{~cm} \\
d=0.84^{*}\end{array}$ \\
\hline $\begin{array}{c}\text { Bipodal/ unipodal } \\
\text { Sitting/ standing with feet together/ } \\
\text { separate/ one leg. Spine neutral } \\
\text { position }\end{array}$ & $\begin{array}{c}8 \times 30 \mathrm{~s} \\
\text { Total: } 240 \mathrm{~s}\end{array}$ & Feeling tightness, but no pain & Classic sit-and-reach & $\begin{array}{c}E G 1: D=1.2 \mathrm{~cm} \\
d=0.17^{*} \\
E G 2: D=1.6 \mathrm{~cm} \\
d=0.23^{*}\end{array}$ \\
\hline $\begin{array}{c}\text { Unipodal } \\
\text { Standing/ lying with one leg. Spine } \\
\text { neutral position }\end{array}$ & $\begin{array}{c}\text { EG1: } 5 \text { × } 30 \mathrm{~s} \text { (static passive) } \\
\text { EG2: } 8 \text { × 10-10 s (PNF: contract-relax) } \\
\text { EG3: } 8 \times 10-10 \mathrm{~s} \text { (PNF: hold-relax) } \\
\text { EG4: } 10 \times 30 \mathrm{~s} \text { (active dynamic) } \\
\text { Total: } 150-300 \mathrm{~s}\end{array}$ & Feeling tightness & Passive knee extension & $\begin{array}{c}E G 1: D=24.8^{\circ} \\
d=2.18^{*} \\
E G 2: D=24.7^{\circ} \\
d=2.26^{*} \\
E G 3: D=25.3^{\circ} \\
d=2.41^{*} \\
E G 4: D=24.6^{\circ} \\
d=2.34^{*}\end{array}$ \\
\hline $\begin{array}{c}\text { Bipodal } \\
\text { EG1: Classic sit-and-reach } \\
\text { EG2: Sitting with feet together } \\
\text { EG3: Sitting/ standing with feet } \\
\text { together/ Sitting with feet separate. } \\
\text { EG1-3: Spine flexion }\end{array}$ & $\begin{array}{l}\text { EG1: } 4 \times 2 \mathrm{~s} \\
\text { EG2: } 4 \times 20 \mathrm{~s} \\
\text { EG3: } 12 \times 20 \mathrm{~s} \\
\text { Total: } 8-240 \mathrm{~s}\end{array}$ & $?$ & Classic sit-and-reach & $\begin{aligned} E G 1: D & =0.8 \mathrm{~cm} \\
d & =0.11^{*} \\
E G 2: D & =2.4 \mathrm{~cm} \\
d & =0.32^{*} \\
E G 3: & D=4.4 \mathrm{~cm} \\
d & =0.59^{*}\end{aligned}$ \\
\hline$?$ & $\begin{array}{l}3 \times 15 \mathrm{~s} \\
\text { Total: } 45 \mathrm{~s}\end{array}$ & Moderate, no pain & $\begin{array}{l}\text { Stand-and-reach } \\
\text { Passive straight leg raise }\end{array}$ & $\begin{array}{c}D=3.57 \mathrm{~cm} \\
d=?^{*} \\
D=7.69^{\circ} \\
d=?{ }^{*}\end{array}$ \\
\hline $\begin{array}{l}\text { Bipodal/ unipodal } \\
\text { Standing with feet together/ one leg; } \\
\text { Lying with one leg. Spine neutral } \\
\text { position }\end{array}$ & $\begin{array}{l}12 \times 15 \text { s (warm-up) } \\
6 \times 15 \text { s (cool-down) } \\
\text { Total: } 270 \mathrm{~s}\end{array}$ & $?$ & Passive straight leg raise & $\begin{array}{c}D=9.15 \mathrm{~cm} \\
d=0.94^{*}\end{array}$ \\
\hline $\begin{array}{c}\text { Bipodal } \\
\text { Standing with feet together. Spine } \\
\text { neutral position }\end{array}$ & $\begin{array}{l}9 \times 20 \text { s (warm-up) } \\
6 \times 20 \text { s (cool-down) } \\
\text { Total: } 300 \mathrm{~s}\end{array}$ & Feeling tightness, but no pain & Classic sit-and-reach & $\begin{array}{c}D=9.53 \mathrm{~cm} \\
d=1.35^{*}\end{array}$ \\
\hline $\begin{array}{c}\text { Unipodal } \\
\text { Standing (EG2)/ lying (EG1) with one } \\
\text { leg. Spine neutral position }\end{array}$ & $\begin{array}{c}\text { EG1: } 6 \times 5-5 \mathrm{~s} \text { (stretch-eccentric) } \\
\text { EG2: } 1 \times 30 \mathrm{~s} \\
\text { Total: } 30-60 \mathrm{~s}\end{array}$ & Feeling tightness & Passive knee extension & $\begin{aligned} E G 1: D & =11.62^{\circ} \\
d & =1.81^{*} \\
E G 2: D & =10.88^{\circ} \\
d & =1.64^{*}\end{aligned}$ \\
\hline $\begin{array}{c}\text { Unipodal } \\
\text { Standing with one leg. Spine neutral } \\
\text { position }\end{array}$ & $\begin{array}{l}3 \times 30 \mathrm{~s} \\
\text { Total: } 90 \mathrm{~s}\end{array}$ & Feeling tightness & Passive knee extension & $\begin{array}{c}D=7.1^{\circ} \\
d=1.04^{*}\end{array}$ \\
\hline $\begin{array}{c}\text { Bipodal } \\
\text { Sitting with feet separate. Spine } \\
\text { neutral position }\end{array}$ & $\begin{array}{l}300 \mathrm{~s} \text { (warm-up) } \\
120 \mathrm{~s} \text { (cool-down) } \\
\text { Total: } 420 \mathrm{~s}\end{array}$ & $?$ & Classic sit-and-reach & $\begin{aligned} D & =7.6 \mathrm{~cm} \\
d & =1.14^{*}\end{aligned}$ \\
\hline $\begin{array}{c}\text { Bipodal } \\
\text { Sitting with feet together. Spine } \\
\text { flexion }\end{array}$ & $\begin{array}{c}\text { EG1-7: } \\
\text { EG1: static active } \\
\text { EG2: static passive } \\
\text { EG3: static mix } \\
\text { EG4: dynamic active } \\
\text { EG5: dynamic passive } \\
\text { EG6: dynamic mix } \\
\text { EG7: } \text { Kabat method } \\
\text { Total: } 120 \mathrm{~s}\end{array}$ & $?$ & Classic sit-and-reach & $\begin{array}{l}D=? \\
d=?^{*}\end{array}$ \\
\hline
\end{tabular}


Electronic databases search results $(n=5,861)$

-Web of Science $(n=1,619)$

- Scopus $(n=1,641)$

- SportDiscus $(n=1,284)$

- CINAHL $(n=653)$

- $\operatorname{ERIC}(n=49)$

- ProQuest Education Journals $(n=110)$

- Cochrane Library Plus $(n=296)$

- Applied Social Science Journals $(n=39)$

- International Bibliography of the Social Sciences $(n=2)$

- ProQuest Dissertations and Thesses $(n=168)$

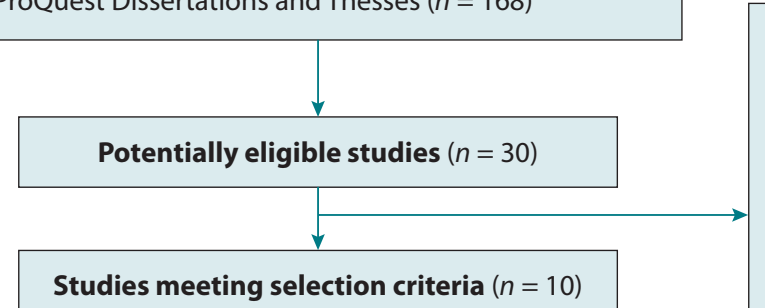

Studides excluded $(n=5,861)$

- Not relevant to apparently healthy participants

- Hamstring extensibility is not measured before and after teh program

- Participants are aged less than 12 years old

- Not include control group

- Programs include strength and/or aerobic exercises in addition to stretching exercises

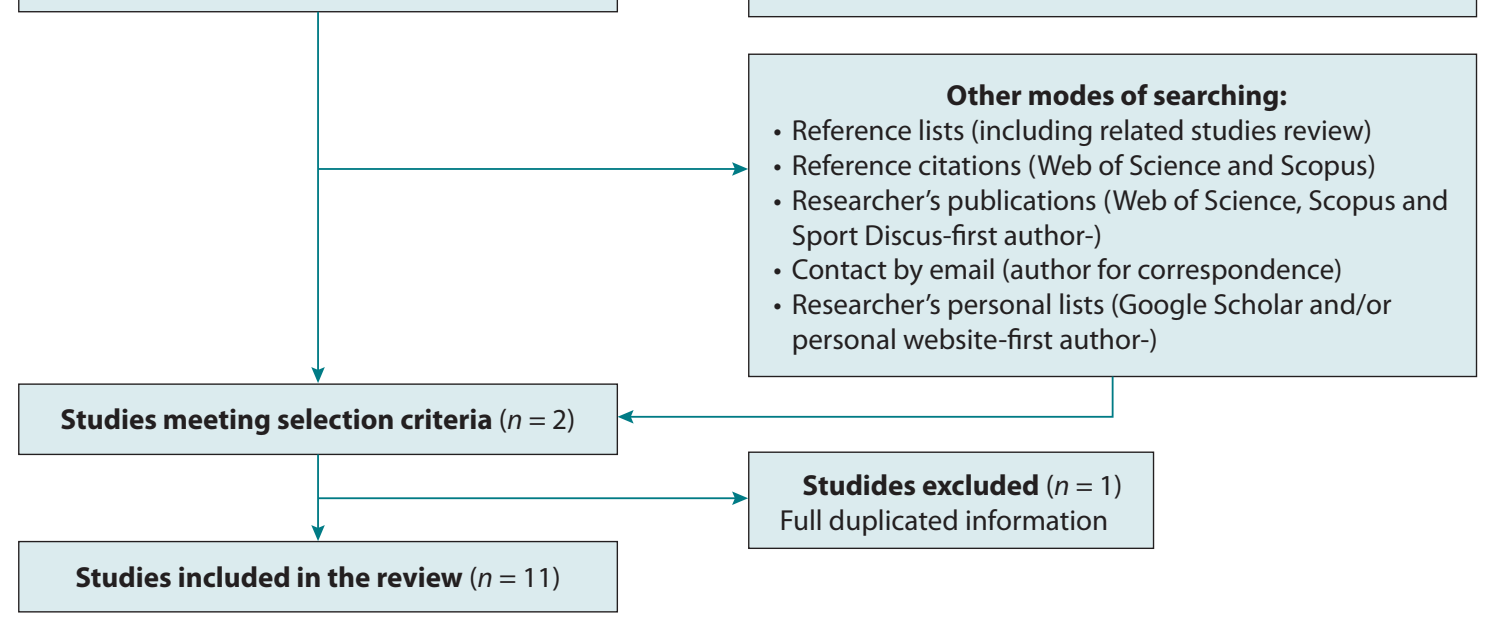

Figure 1. Flow chart of studies selection process

stretching programs for at least five weeks had a statistically significant improvement in students' hamstring extensibility levels, the effect of the stretching program trended to increase with the duration of the program (e.g., median $d$ values for the CSR: shortterm, 5-6 weeks: 0.22; middle-term, 8-12 weeks: 0.84, and long-term, 31-32 weeks: 1.24). However, since any within-study comparison was found, due to the disparity in the studies program characteristics, these conclusions should be taken with caution. Future studies that compared the effect of the duration of the program are needed.

Regarding the frequency of the program, the present systematic review found studies examining the effect of stretching programs performed from one to five times per week. The results showed that the stretching programs for at least once a week had a statistically significant improvement in students' ham- string extensibility levels. However, the effect sizes for the program performed once a week was very low $(d=0.17)$, so at least twice a week is recommended. Mayorga-Vega et al. (2015) compared the effect of a PE-based stretching program performed once and twice a week. Although these authors found that the students of both experimental groups improved statistically significantly their hamstring extensibility compared with the control group students ( $p<$ 0.01 ), no statistically significant differences between the two experimental groups were found $(p>0.05)$. However, due to the fact that all the lineal test-based studies performed the stretching program twice a week (but Mayorga-Vega et al. 2015 that also examined once a week) and angular test-based were three and five times (except Sainz de Baranda, 2009 that examined twice a week) any trend could be explored between other frequencies. Additional studies that 
compare the effect of different frequencies of the stretching program are required.

Regarding the volume of the program, the present systematic review found a high variability between studies, because there were studies examining the effect of stretching programs performed from a total volume of $8 \mathrm{~s}$ to $300 \mathrm{~s}$ per session (from 1 to 12 set, and from $2 \mathrm{~s}$ to $60 \mathrm{~s}$ per set). Although the results showed that the stretching programs for at least $8 \mathrm{~s}$ (4 $\times 2$ s) had a statistically significant improvement in students' hamstring extensibility levels, the magnitude effect was very low $(d=0.11)$. Thus, a total volume per session of at least 30-60 s seems to be recommended. Kamandulis et al. (2013) compared the effect of a stretching program performed with a volume per session of $4 \times 2 \mathrm{~s}(8 \mathrm{~s}), 4 \times 20 \mathrm{~s}(80 \mathrm{~s})$ and $12 \times 20 \mathrm{~s}$ (240 s). Although these authors found that the three groups found statistically significant improvement of hamstring extensibility, the students that performed a total of $240 \mathrm{~s}$ per session increased more than those who performed $80 \mathrm{~s}$ and $8 \mathrm{~s}$.

Regarding the intensity of the program, the present systematic review found that in all the studies were defined by the stretch perceived by the subject during the exercise execution. The experimental group students were asked to perform the stretching exercises when the stretched position was held gently until the end point of the range of motion was reached (i.e., stretch to the point of feeling tightness, but no pain). However, some of the studies did not report the intensity of the stretch used (Kamandulus et al., 2013; Rodriguez et al., 1999; Sainz de Baranda, 2009; Vidal, 1995). Future studies should control the intensity of the program assisted by objective instruments, as well as future studies should compare the effect of a light and moderate intensity.

\section{Stretching exercises and stretching technique}

Regarding the stretching exercises, in the most studies stretching exercises were performed correctly sensing and locating the stretch, properly positioning the spine, with curvatures of the dorsal and lumbar spine within normality (except for Kamandulis et al., 2013, and Vidal et al., 1995). The aligned column eliminates the increase in dorsal kyphosis that would be compensated for the limitation of the movement of the pelvis (Rodríguez \& Santonja, 2001). However, bipodal exercises were also commonly used, which it needs a major control to maintain the column aligned (López Miñarro et al., 2011). Additionally, in all the studies, the postures were adopted gently and slowly until the final amplitude without feeling pain.
The sitting hip flexion and supine decubitus exercises with the knees extended were selected in some studies, due to the equilibrium conditions that guarantee during the execution and the stability of the knee in extension (Becerra-Fernández et al., 2016; Mayorga-Vega et al., 2015; Rodríguez et al. 1999, 2008; Sainz de Baranda, 2009; Useros \& Campos, 2011). In addition to these postures some studies perform standing exercises (Mayorga-Vega et al., 2015; Nelson \& Bandy, 2004; Reid \& McNair, 2004; Useros \& Campos, 2011). A pattern that increases the effectiveness of hamstring stretching exercises is the anteversion of the pelvis (Rodríguez \& Santonja, 2001). Some of the programs take into account the placement of the pelvis in anteversion (Reid \& McNair, 2004; Sainz de Baranda, 2009).

Regarding the stretching technique, most of the programs included static stretching techniques to improve flexibility. The static technique consists in a stretching maneuver where the target muscle is stretched slowly, while remaining relaxed and without muscle intervention in the involved joints, with certain intensity and subsequently that range of motion is held the established time. Since the static technique has showed to be effective to improve students' hamstring extensibility (in 10 of the 11 studies were used) and contributes to a greater control of the aligned arrangement of the spine, it seems that static technique is mainly recommended in high school students. Nevertheless, as several authors suggest (e.g., Behm et al., 2011; Turki-Belkhiria et al., 2014), dynamic stretching exercises may not be harmful when practiced in a soft and controlled way. In this line, three studies showed the effectiveness and safety of a dynamic stretching program (Becerra-Fernández et al., 2016; Van Rensburg \& Coetzee, 2014; Vidal, 1995). Two studies were interested in determining whether there was a significant difference among the static and dynamic stretching techniques (Van Rensburg \& Coetzee, 2014; Vidal, 1995). The results indicated there were not statistically significant differences between the static and dynamic techniques in order to improve students' hamstring extensibility. Therefore, future research might be interesting to apply similar programs using dynamic methods as active rebounds in high school students.

On the other hand, studies that compare different stretching techniques found similar results (Reid \& McNair, 2004; Sainz de Baranda, 2009; Useros \& Campos, 2011), except for the Useros and Campos's (2011) study where the students that used the Active Global Stretching (AGS) technique of obtained results slightly higher than the others. Stretching of muscle chains may be more effective at improving hamstring extensibility than analytical stretching. 


\section{Detraining and maintenance}

Until now most studies only have focused on the benefits and gains existing in hamstring extensibility after application of stretching programs between two or more groups. However, only a few studies have examined how long they can retain these gains after a development program school-aged children (Becerra-Fernández et al., 2016; Mayorga-Vega et al., 2014c; Mayorga-Vega et al., 2014d; Merino-Marban et al., 2015). Particularly, only one study has been performed this feature in high school students (Becerra-Fernández et al., 2016).

Current scientific information about the flexibility detraining is really scarce and contradictory (Cipriani et al., 2012; Rancour, Holmes \& Cipriani, 2009; Willy, Kyle, Moore, Chleboun, 2001), especially among school age children (Merino-Marban et al., 2015; Mayorga-Vega et al., 2014c; Mayorga-Vega et al., 2014d). Becerra-Fernández et al. (2016) observed that although a PE-based dynamic stretching intervention is effective to improve hamstring extensibility among high school school students, after four weeks of detraining students' flexibility reverts back to their baseline levels. Similarly, although Mayorga-Vega et al. (2014d) observed that primary schoolchildren retained significant gains, all the previous studies with primary schoolchildren found a statistically significant loss of hamstring extensibility after five weeks of detraining (Merino-Marban et al., 2015; Mayorga-Vega et al., 2014c).

Therefore, since after four to five weeks of flexibility detraining the effect of the stretching program are lost, PE teachers should continue training students' flexibility after a shorter detraining period in order to maintain the gains obtained in the previous semesters. Additionally, since the limited time allocation in PE (Hardman, Murphy, Routen, \& Tones, 2014), teachers should teach to students how to correctly stretch and promote stretching habits. Since stretching programs cannot be allocated a large part of PE time, previous authors have suggested that PE teachers should include a maintenance program with reduced volume in order to retain students' flexibility levels gained during previous semesters (Viciana et al., 2014a; Viciana et al., 2014b). This way, apart from maintaining the flexibility levels previously obtained, such programs would allow teachers to address other PE curricular contents at the same time (Mayorga-Vega, Viciana \& Cocca, 2013).

In this line, Becerra-Fernández et al. (2016) observed the effects of a dynamic stretching maintenance program on hamstring extensibility in female high school students. The results of this study showed that a stretching maintenance program carried out only two minutes per session (i.e., the half volume) improves students' hamstring extensibility. Unfortunately, it must be highlighted that the values before the "maintenance" program were at the baseline levels and, therefore, strictly speaking it should be considered "resumption" or "re-development" instead of "maintenance". However, since the control students showed a significant decrease throughout the time, it seems that this program would allow avoid the apparently normal decline of flexibility at this age.

\section{Test protocol}

Regarding the test protocol, only five studies used angular tests to assess students' hamstring extensibility (Nelson \& Bandy, 2004; Reid \& McNair, 2004; Sainz de Baranda, 2009; Useros \& Campos, 2011; Van Rensburg \& Coetzee, 2014). Due to the necessity of several instruments (i.e., a stretcher, Lumbosant or similar device, and a goniometer or inclinometer), two or more qualified evaluators, and time constraints, the use of these angular tests seem to be limited in several studies such as in the school setting (Becerra-Fernández et al., 2016; Kamandulis, Emeljanovas \& Skurvydas 2013; Rodríguez et al., 1999; Rodríguez et al., 2008; Vidal, 1995). Since flexibility evaluation with goniometers and inclinometers are really sensitive methods, their use requires a certain technical qualification (Castro-Piñero et al., 2009). For example, for the Passive straight leg raise test, which is the most extended and recommend test for schoolaged children (Mayorga-Vega et al., 2014), besides the variability in the determination of the raise leg end point based on the evaluated individual reported that the muscle tightness turn to pain and/ or the assistant evaluator palpable onset of posterior pelvic tilt, small changes in the grade of aligning of the goniometer axis with the hip joint, the aligning of the goniometer arms with the trunk and femur, the knee extension and ankle position of the evaluated leg, the contact of the contralateral leg, the external hip rotation, the pelvis rotation in the longitudinal axis and/ or the sagittal pelvis tilt may significantly affect the test score (López Miñarro et al., 2008; López-Miñarro et al., 2009; Mayorga-Vega et al., 2014). Additionally, angular hamstring extensibility tests require between two and three evaluators for each measure (Nelson \& Bandy, 2004; Sainz de Baranda, 2009; López Miñarro et al., 2008; López-Miñarro et al., 2009). For example, while the main evaluator raises the leg and record the score, an assistant evaluator has to maintain the con- 
tralateral leg extended and in contact with the stretcher, avoiding the external rotation, as well as the pelvis rotation in the longitudinal axis; and a second assistant evaluator have to fix and control the sagittal pelvis tilt (e.g., López Miñarro et al., 2008; López-Miñarro et al., 2009). Finally, since the individual has to lie down on the stretcher, the assistant evaluators has to fix the contralateral leg and pelvis, the main evaluator has to align the axis and the two arms of the goniometer, and at least two measures are require for each leg, they also are more time consuming compared with other protocols such as the lineal tests (Mayorga-Vega et al., 2014).

That is why the CSR is the most frequently used flexibility test in school setting because its procedure is simple, easy to administer, and only requires a one minimal trained evaluator (Castro-Piñero et al., 2009; López Miñarro et al., 2008). According to Mayorga-Vega, Merino-Marban and Viciana (2014a) the CSR test has a moderate mean criterion-related validity for estimating hamstring extensibility $\left(r_{\mathrm{p}}=0.67\right)$, but not for estimating lumbar muscles extensibility that was very poor $\left(r_{\mathrm{p}}=0.26\right)$. Consequently, when the use of angular tests is limited such as in a school setting or in large scale studies, scientists and practitioners could use the CSR test as a useful alternative for hamstring extensibility estimation (Mayorga-Vega et al., 2014). Only Useros and Campos (2011) examined the effect of a stretching program with both angular and lineal tests. However, since they only reported the change score, comparable effects sizes such as the $d$ value could not be calculated. Regarding the between-study comparison, the median value showed that a significant lower effect magnitude (i.e., $d$ value) was found among the intervention program that was evaluated with the lineal tests $(d=0.45)$ than with the angular test $(d=1.99)$. However, since several characteristics of the individual and programs could also vary between these studies, studies that compare the effect sizes reached with both kinds of tests are required. Additionally, as in the application of any physical fitness field test, it must be aware that the CSR test score is simply estimation and not a direct measure of hamstring extensibility (Mayorga-Vega et al., 2014). Therefore, future randomized controlled studies that examine the effect of stretching programs by angular tests are required. Meanwhile those studies are performed, the findings with the lineal tests are also valuables. Firmer conclusions should await the accumulation of a larger number of cluster-randomized controlled trial studies sigle-blinded evaluated with angular tests in the PE setting.

A limitation of the studies was the fact that they did not take into account the alignment of the rachis during the stretching exercises and used the CSR is whether the improvements could be due to changes in the extensibility or changes in the disposition sagittal of the rachis (Kamandulis et al., 2013; Vidal, 1995). However, it is assumed that those studies that took into account the adequate alignment of the spine during the exercises would have avoided improvements due to changes in the sagittal arrangement of the spine (Becerra et al., 2016; Mayorga-Vega et al., 2015; Rodriguez et al., 1999, 2008).

\section{Conclusions}

A Physical Education-based stretching program produces a significant improvement of high-school students' hamstring extensibility levels. The results suggested that students should performed stretching programs at least for a duration of 5-6 weeks, a frequency of twice a week, and a volume per session of 30-60 s (20-30 s per set) to obtain improvements on hamstring extensibility. Stretching programs with higher duration, frequency and volume seems to obtain greater effects. However, after a four-week detraining period, students reverted back to their baseline levels. Although the most studies obtained flexibility improvements using static techniques, dynamic stretching exercises performed in a controlled manner also produced improvements and they were safety. Stretching programs should be included in Physical Education classes, specifically during the warm-up and the cool-down periods in order to improve hamstring extensibility. Teachers should implement stretching programs to improve the students' flexibility during the Physical Education classes. 


\section{REFERENCES}

Becerra-Fernández, C. A., \& Merino-Marban, R. (2015). Efficacy of hamstring stretching programs in schoolchildren. A systematic review. Timisoara Physical Education and Rehabilitation Journal, 8(15), 36-43. doi:10.1515/tperj-2015-0015

Becerra-Fernández, C. A., Merino-Marban, R., \& Mayorga-Vega, D. (2016). Effect of a physical education-based dynamic stretching program on hamstring extensibility in female high school students. Kinesiology, 48(2), 258-266.

Behm, D. G., Plewe, S., Grage, P., Rabbani, A., Beigi, H. T., Byrne, J. M. \& Button, D. C. (2011). Relative static stretch-induced impairments and dynamic stretch-induced enhancements are similar in young and middle-aged men. Applied Physiology, Nutrition, and Metabolism, 36(6), 790-797. doi:10.1139/h11-107

Borenstein, M., Hedges, L., Higgins, J., \& Rothstein, H. (2009). Introduction to meta-analysis. United Kingdom: Wiley.

Borras, X., Comella, A., Marín, F., Comella, R. R., \& Cirera, E. (2007) Applicability of goniometry through videography in the follow-up of flexibility programs. Biomecánica, 15(1):28-33.

Brodersen, A., Pedersen, B., \& Reimers, J. (1994). Incidence of complaints about heel, knee and back related discomfort among Danish children, possible relation to short muscles. Ugeskrift fot Laeger, 156 2243-2245.

Castro-Piñero, J., Chillón, P., Ortega, F. B., Montesinos, J. L., Sjöström, M., \& Ruiz, J. R. (2009). Criterion-related validity of sit-and-reach and modified sit-and-reach test for estimating hamstring flexibility in children and adolescents aged 6-17 years. International Journal of Sports Medicine, 30, 658-662. doi:10.1055/s-0029-1224175

Castro-Piñero, J., Girela-Rejón, M. J., González-Montesinos, J. L., Mora, J., Conde-Caveda, J., Sjöström, M., \& Ruiz, J. R. (2013). Percentile values for flexibility tests in youths aged 6 to 17 years: Influence of weight status. European Journal of Sport Science, 13(2), 139-148. doi:1 0.1080/17461391.2011.606833

Chodzko-Zajko, W. J., Proctor, D. N., Fiatarone Singh, M. A., Minson, C. T., Nigg, C. R., Salem, G. J., \& Skinner, J. S. (2009). Exercise and physical activity for older adults. Medicine \& Science in Sports \& Exercise, 41(7), 1510-1530. doi:10.1249/MSS.0b013e3181a0c95c

Cipriani, D. J., Terry, M. E., Haines, M. A., Tabibnia, A. P., \& Lysanova, O. (2012). Effect of stretch frequency and sex on the rate of gain and rate of loss in muscle flexibility during a hamstring-stretching program: A randomized single-blind longitudinal study. Journal of Strength and Conditioning Research, 26(8), 2119-2129. doi:10.1519/JSC.0b013e31823b862a

Cohen, J. (1992). A power primer. Quantitative Methods in Psychology, 112(1), 155-159.

Coledam, D. H. C., Arruda, G. A., \& Ramos de Oliveira, A. (2012). Chronic effect of static stretching performed during warm-up on flexibility in children. Revista Brasileira de Cineantropometria e Desempenho Humano, 14, 296-304. doi:10.5007//1980-0037.2012v14n3p296

Feldman, D. E., Shrier, I., Rossignol, M., \& Abenhaim, L. (2001). Risk factors for the development of low back pain in adolescence. American Journal of Epidemiology, 154(1), 30-36. doi:10.1093/aje/154.1.30

Fisk, J. W., Baigent, M. L., \& Hill, P. D. (1984). Scheuermann's disease. Clinical and radiological survey of 17 and 18 year olds. American Journal of Physical Medicine, 63(1), 18-30.

Hardman, K., Murphy, C., Routen, A., \& Tones, S. (2014). UNESCO-NWCPEA: World-wide survey of school Physical Education. París: United Nations Educational, Scientific and Cultural Organization.

Harreby, M., Neergaard, K., Jessen T., Larsen E., Storr-Paulsen A., Lindahl A., Laegaard E. (1999). Risk factors for low back pain in a cohort of 1389 Danish school children: An epidemiologic study. European Spine Journal, 8, 444-450. doi:10.1007/s005860050203

Harvey, J., \& Tanner, S. (1991). Low back pain in young athletes: A practical approach. Sports Medicine, 12(6), 394-406. doi:10.2165/00007256199112060-00005

Hestbaek, L., Leboeuf-Yde, C., Kyvik, K.O., \& Manniche, C. (2006). The course of low back pain from adolescence to adulthood. Eight year follow up of 9600 twins. Spine, 31(4), 468-472.
Jones, M. A., Stratton, G., Reilly, T., \& Unnithan, V.B. (2005). Biological risk indicators for recurrent non-specific low back pain in adolescents. British Journal of Sports Medicine, 39(3), 137-140. doi:10.1136/ bjsm.2003.009951

Kamandulis, S., Emeljanovas, A., \& Skurvydas, A. (2013). Stretching exercise volume for flexibility enhancement in secondary school children. The Journal of Sports Medicine and Physical Fitness, 53(6), 687-692.

Kanásová, J. (2008). Reducing shortened muscles in 10-12-year-old boys through a physical exercise program. Medicina Sportiva, 12,115-123. doi:10.2478/v10036-008-0022-x

Kujala, U. M., Taimela, S., Salminen, J. J., \& Oksanen, A. (1994). Baseline anthropometry, flexibility and strength characteristics and future low-back pain in adolescent athletes and nonathletes. Scandinavian Journal of Medicine and Science in Sports, 4(3), 200-205. doi:10.1111/j.1600-0838.1994.tb00426.x

López Miñarro, P. A. (2001). Ejercicios desconsejados en la actividad física. Detencción y alternativas. Barcelona: Inde.

López Miñarro, P. A., Sainz de Baranda, P., Yuste Lucas, J. L., \& Rodríguez García, P. L. (2008). Validity of the unilateral sit-and-reach test as measure of hamstring muscle extensibility. Comparison with other protocols. Cultura, Ciencia y Deporte, 3, 87-92. doi:10.12800/ccd. v3i8.199

López-Miñarro, P. A., \& Alacid, F. (2009). Influence of hamstring muscle extensibility on spinal curvatures in young athletes. Science \& Sports, 25(4), 188-193. doi:10.1016/j.scispo.2009.10.004

Mayorga-Vega, D., Merino-Marban, R., Real, J., \& Viciana, J. (2015) A physical education-based stretching program performed once a week also improves hamstring extensibility in schoolchildren: A cluster-randomized controlled trial. Nutricion Hospitalaria, 32(4), 17151721. doi:10.3305/nh.2015.32.4.930

Mayorga-Vega, D., Merino-Marban, R., Sánchez-Rivas, E., \& Viciana, J. (2014c). Effect of a short-term static stretching training program followed by five weeks of detraining on hamstring extensibility in children aged 9-10 years. Journal of Physical Education and Sport, 14(3), 355-359. doi:10.7752/jpes.2014.03054

Mayorga-Vega, D., Merino-Marban, R., Vera-Estrada, F., \& Viciana, J. (2014d). Effect of a short-term physical education-based flexibility program on hamstring and lumbar extensibility and its posterior reduction in primary schoolchildren. Kinesiology, 46(2), 227-233.

Mayorga-Vega, D., Merino-Marban, R., \& Viciana, J. (2014a). Criterionrelated validity of sit-and-reach tests for estimating hamstring and lumbar extensibility: A meta-analysis. Journal of Sports Science and Medicine, 13(1), 1-14.

Mayorga-Vega, D., Viciana, J., \& Cocca, A. (2013). Effects of a circuit training programme on muscular and cardiovascular endurance and their maintenance in schoolchildren. Journal of Human Kinetics 37, 153-160. doi:10.2478/hukin-2013-0036

Merino Marban, R., \& Fernández Rodriguez, E. (2009). Review of the types and classifications of flexibility. New proposed classification. Revista Internacional de Ciencias del Deporte, 5(16), 52-70. doi:10.5232/ ricyde2009.01604

Merino Marban, R., López Fernández, I., Torres Luque, G., \& Fernández Rodríguez, E. (2011). Concepts about flexibility and related terms. A systematic review. Trances, 3(1), 1-32.

Merino-Marban, R., Mayorga-Vega, D., Fernández-Rodríguez, E., Vera Estrada, F., \& Viciana, J. (2015). Effect of a physical education-based stretching programme on sit-and-reach score and its posterior reduction in elementary schoolchildren. European Physical Education Review 21(1), 83-92. doi:10.1177/1356336X14550942

Mikkelsson, L. O., Nupponen, H., Kaprio, J., Kautiainen, H., Mikkelsson, M., \& Kujala, U. (2006). Adolescent flexibility, endurance strength, and physical activity as predictors of adult tension neck, low back pain, and knee injury: A 25 year follow up study. British Journal of Sports Medicine, 40(2), 107-113. doi:10.1136/bjsm.2004.017350

National Association for Sports and Physical Education. (2005). Physical education for lifelong fitness: The physical best teacher's guide. Leeds: Human Kinetics. 
Nelson, R. T., \& Bandy, W. D. (2004). Eccentric training and static stretching improve hamstring flexibility of high school males. Journal of Athletic Training, 39, 254-258.

Ortega, F. B., Ruiz, J. R., Castillo, M. J., \& Sjöström, M. (2008). Physical fitness in childhood and adolescence: A powerful marker of health. International Journal of Obesity, 32, 1-11. doi:10.1038/sj.ijo.0803774

Ortega, F. B., Ruiz, J. R., Castillo, M. J., Moreno, L. A., González-Gross, M., \& Gutiérrez, A. (2005). Low level of physical fitness in Spanish adolescents. Relevance for future cardiovascular health (AVENA Study). Revista Española de Cardiología, 58(8), 898-909. doi:10.1016/ S1885-5857(06)60372-1

Rancour, J., Holmes, C. F., \& Cipriani, D. J. (2009). The effects of intermittent stretching following a 4-week static stretching protocol: A randomized trial. Journal of Strength and Conditioning Research, 23(8), 2217-2222. doi:10.1519/JSC.0b013e3181b869c7

Reid, D. A., \& McNair, P. J. (2004). Passive force, angle and stiffness changes after stretching of hamstring muscles. Medicine and Science in Sports and Exercise, 36, 1944-1948. doi:10.1249/01. MSS.0000145462.36207.20

Rodríguez, P. L., \& Santonja, F. (2001). Repercusiones posturales con los estiramientos en flexión de tronco y las pruebas de distancia dedosplanta y distancia dedos-suelo. Apunts Educación Física y Deportes, 65, 64-70.

Rodríguez García, P. L., Santonja Medina, F., Canteras Jornada, M., Delgado Fernández, M., Fernández Piñera, J., \& Balsalobre Marín, J. (1999). Improving the hamstring elasticity inside a school program. Selección, 8(4):157-164.

Rodríguez, P. L., Santonja, F. M., López-Miñarro, P. A., Sáinz de Baranda, J. L., \& Yuste, J. L. (2008). Effect of physical education stretching program on sit-and-reach score in schoolchildren. Science \& Sports, 23(3-4), 170-175.

Sainz de Baranda, P. (2009). Flexibility training in physical education: Intervention program. Cultura, Ciencia y Deporte, 4(10), 33-38.

Sánchez Rivas, E., Mayorga-Vega, D., Fernández-Rodríguez, E., \& Merino-Marbán, R. (2014). Effect of a hamstring stretching program during physical education lessons in primary education. Journal of Sport and Health Research, 6(2), 159-168.

Santonja, F., Rodríguez, P. L., Sainz de Baranda, P., \& López Miñarro, P. A. (2004). Role of physical education teachers with regard to spinal misalignments. Selección, 13(1), 5-17.

Santonja, F., Sainz de Baranda, P., Rodríguez, P. L., López, P. A., \& Canteras, M. (2007). Effects of frequency of static stretching on straight leg raise in elementary school children. Journal of Sports Medicine and Physical Fitness, 47(3), 304-308.

Sjölie, A. N. (2004). Low back pain in adolescents is associated with poor hip mobility and high body mass index. Scandinavian Journal of Medicine \& Science in Sports, 14(3), 168-175. doi:10.1111/j.16000838.2003.00334.x

Standaert, C. J., \& Herring, S. A. (2000). Spondylolysis: A critical review. British Journal of Sports Medicine, 34, 415-422. doi:10.1136/ bjsm.34.6.415

Thacker, S. B., Gilchrist, J., Stroup, D. F., \& Kimsey, C. D. J. (2004). The impact of stretching on sports injury risk: A systematic review of the literature. Medicine and Science in Sports and Exercise, 36(3), 371-378. doi:10.1249/01.MSS.0000117134.83018.F7

Turki-Belkhiria, L., Chaouachi, A., Turki, O., Chtourou, H., Chtara, M., Chamari K.,... Behm, D. G. (2014). Eight weeks of dynamic stretching during warm-ups improves jump power but not repeated or single sprint performance. European Journal of Sport Science, 14(1), 19-27. doi:10.1080/17461391.2012.726651

Useros, P., \& Campos, M. (2011). Analytical stretching and active global stretching in physical education classes. Fisioterapia, 33(2), 70-78. doi:10.1016/j.ft.2011.02.003

Van Resbourg, L. J., \& Coetzee, F. F. (2014). Effect of stretching techniques on hamstring flexibility in female adolescents. African Journal for Physical, Health Education, Recreation and Dance, 20(3:2), 1237-1248.

Viciana, J., Mayorga-Vega, D., \& Cocca, A. (2014a). Successful learning model in physical education and its maintenance. The intermittent reinforcement applied to physical fitness. Revista Iberoamericana de Psicología del Ejercicio y el Deporte, 9(1), 155-171.

Viciana, J., Mayorga-Vega, D., \& Merino-Marban, R. (2014b). Physical education-based planning for developing and maintaining students' health-related physical fitness levels. In R. Todaro (Ed.), Handbook of physical education research. Role of school programs, children's attitudes and health implications (pp. 237-252). New York: Nova Science Publisher.

Vidal, M. (1995). Evaluation of 7 methods of flexibility development. Apunts, 32, 195-201.

Vidal, M., Vidal, T., Almela, M., \& Vidal, M. (2011). Shortening of the hamstring muscles. Apunts. Educación Física y Deportes, 105, 44-50.

Willy R. W., Kyle B. A., Moore S. A., \& Chleboun G. S. (2001). Effect of cessation and resumption of static hamstring muscle stretching on joint range of motion. Journal of Orthopaedic and Sports Physical Therapy, 31(3), 138-144. doi:10.2519/jospt.2001.31.3.138 